\title{
El Contrato de Permuta en la codificación civil peruana
}

\section{The Bargain Agreement in the Peruvian Civil Coding}

Fernando Vidal Ramírez*https://orcid.org/0000-0003-2607-6719

http://dx.doi.org/10.21503/lex.v18i26.2186

* En ejercicio desde 1962, Lima. Abogado por la Universidad Mayor de San Marcos, Lima. Profesor Universitario. Miembro de la Comisión Revisora del Código Civil y de la Comisión de las Naciones Unidas para el Derecho Mercantil Internacional (UNCITRAL). Presidente de la Academia Peruana de Derecho. Miembro del Consejo Consultivo del INDECOPI y Presidente de la Comisión Consultiva de Justicia. Exdecano del Colegio de Abogados de Lima. Expresidente de la Federación Iberoamericana de Bolsas de Valores. Expresidente de la Bolsa de Valores de Lima. Juez Ad Hoc en la Corte Interamericana de Derechos Humanos. Expresidente del Tribunal de Honor del Pacto Ético Electoral (JNE). Perú.

Correo electrónico: fevidal@vqplaw.com

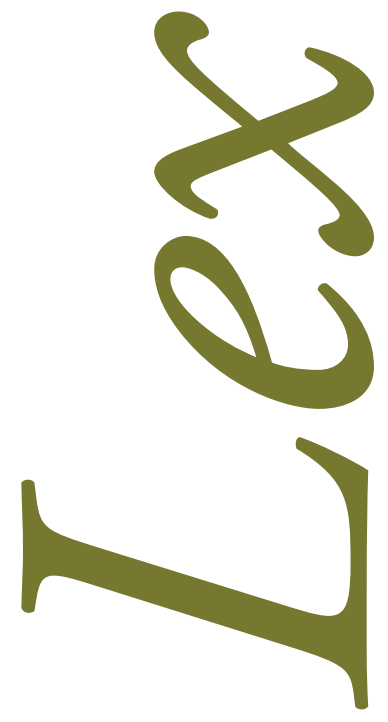




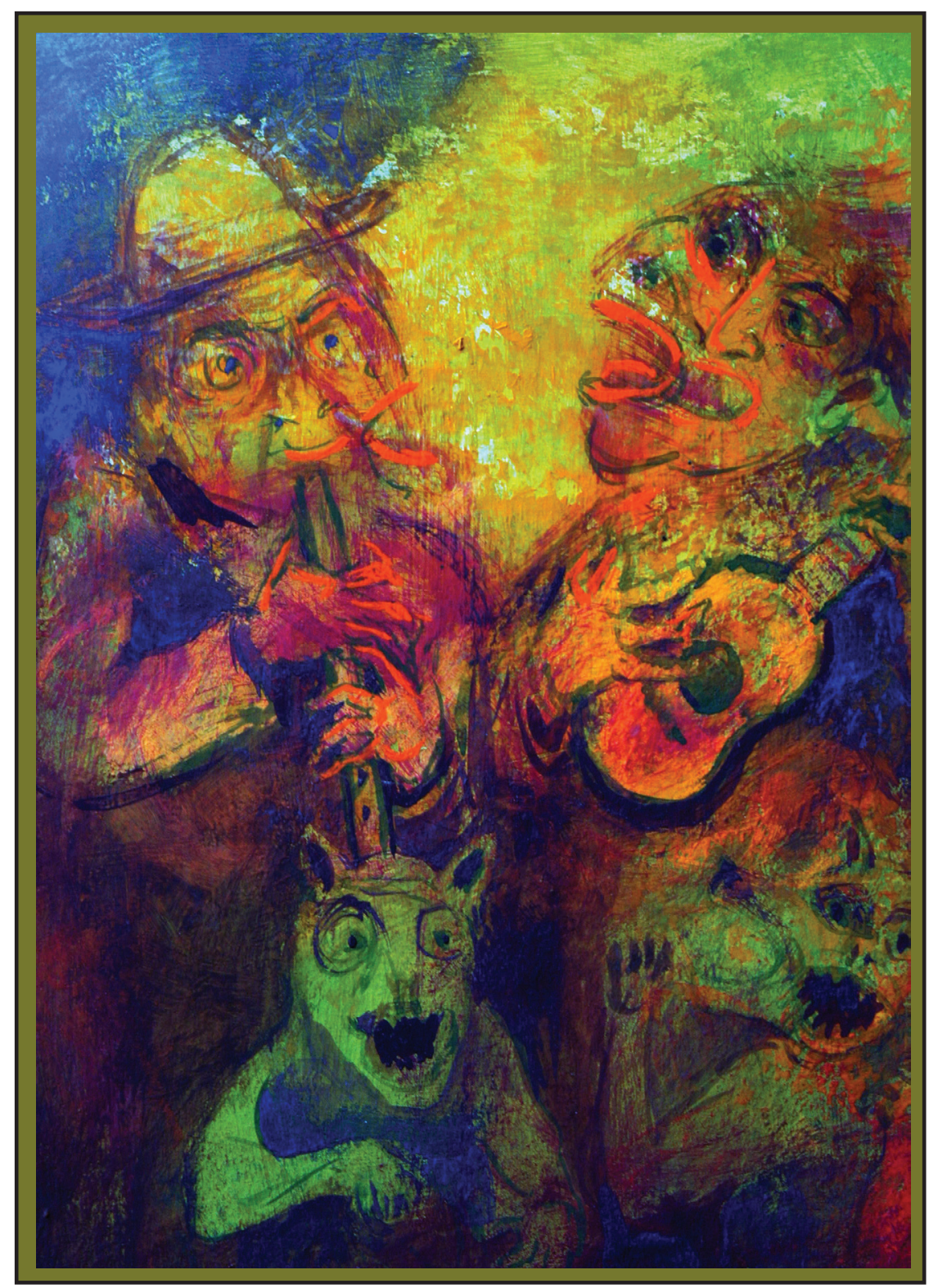

La jarana. Mixto, 1995. Artista plástico peruano, Alberto Quintanilla (Cusco, 1934). 


\title{
RESUMEN
}

El Contrato de Permuta pese a su raigambre romanista y tener asiento en la codificación civil peruana viene siendo tradicionalmente soslayado por la jurisprudencia y en la práctica, pues el Contrato de Compraventa se impone pese a que algunas relaciones jurídicas propiamente las genera una permuta. Así, por ejemplo, cuando se entrega un automóvil usado, cuyo valor es resultado de una tasación, para adquirir uno nuevo pagando, para el efecto, una diferencia igual o que excede el precio del nuevo automóvil, lo que se configura es una permuta conforme al artículo 1531, segundo párrafo ${ }^{1}$ del Código Civil. Sin embargo, y sin tenerse en consideración el acotado artículo 1531, en la práctica se considera este modo de adquirir automóviles, en las circunstancias anotadas, como efectuados a título de compraventa. El Código Civil sólo dedica dos artículos al tratamiento del contrato de permuta, pues el artículo 1602 la conceptúa y el 1603 la somete a las disposiciones de la compraventa, lo que determina no sólo el soslayamiento en que está incurso este contrato, sino que explica su desuso, aunque debe advertirse que la desuetudo no es derogatoria. La circunstancia expuesta motiva el presente estudio del Contrato de Permuta tomando en consideración sus antecedentes históricos, su sustantividad y su adopción por la codificación civil peruana.

Palabras clave: contrato de permuta, código civil art. 1531, 1602, 1603, desuetudo.

\begin{abstract}
The Swap Agreement despite its Romanist roots and having a seat in the Peruvian civil code has traditionally been ignored by jurisprudence and in practice, since the Sale Contract is imposed despite the fact that some legal relationships are properly generated by a swap. Thus, for example, when a used car is delivered, the value of which is the result of an appraisal, to acquire a new one by paying, for this purpose, a difference equal to or exceeding the price of the new car, what is configured is a conforming swap to article 1531, second paragraph of the Civil Code. However, and without taking into consideration the limited article 1531, in practice this way of acquiring automobiles is considered, in the circumstances noted, as carried out by way of sale. The Civil Code only dedicates two articles to the treatment of the swap contract, since article 1602 defines it and 1603 subjects it to the provisions of the sale, which determines not only the circumvention in which this contract is incurred but also explains its disuse, although it should be noted that desuetudo is not derogatory. The exposed circumstance motivates the present study of the Swap Agreement taking into consideration its historical antecedents, its substantivity
\end{abstract}

Key words: swap contract, civil code art. 1531, 1602, 1603, late.ts.

1. 1531.- Si el precio de una transferencia se fija parte en dinero y parte en otro bien, se calificará el contrato de acuerdo con la intención de los contratantes independientemente de la denominación que se le dé. Si no consta la intención de las partes, el contrato es de permuta cuando el valor del bien es igual o excede al del dinero; y de compraventa si es menor. 


\section{ANTECEDENTES HISTÓRICOS}

Al decir de los historiadores del Derecho la permuta es el más antiguo antecedente de los contratos ya que se remonta a los grupos humanos primitivos, pues tuvo su expresión originaria en esa operación rudimentaria que vino a ser el trueque.

El trueque tuvo su origen cuando el ser humano primitivo comenzó la recolección de frutos de la tierra, para luego dedicarse a la caza y posteriormente a la agricultura. Fue así que los frutos primero y las pieles de los animales después le sirvieron de medios de cambio y, cuando se dedicó al pastoreo del ganado, fueron los animales vivos los utilizados para el mismo fin. En una etapa más avanzada la fabricación de objetos contribuyó al desarrollo del trueque hasta la aparición de la moneda en sus formas más rudimentarias.

A este quehacer no fue ajeno el aborigen americano, pues no podía sustraerse a la vida de relación y a su evolución en los territorios que luego fueron objeto de conquista que, en el caso de la española, llegó con la moneda. Pero la moneda no desplazó el trueque, que continuó operando como un medio eficaz para la satisfacción de las necesidades mediante la adquisición de bienes. Sin embargo, la aparición de la moneda fue diferenciando el trueque de la compra, pues en el trueque se entregaba como equivalente una cosa mientras que en la compra se entregaba como equivalente el valor expresados en monedas.

Los antecedentes resumidamente expuestos constituyen la prueba incuestionable de que la permuta antecedió históricamente a la compraventa.

\section{EL DERECHO ROMANO}

El Derecho Romano diseñó a la compraventa como contrato relegando a la permuta al carácter de una simple convención, a un negotium do ut des, en la que las partes debían entregarse recíprocamente cosas.

En los orígenes del Derecho Romano y hasta la Ley de las XII Tablas, la moneda consistía en cabezas de ganado, fueran bueyes o carneros, pecus, vocablo del que deriva pecunia, pecuniario, que se refería al dinero y que hasta hoy mantiene el significado de dinero efectivo, para luego representarse la moneda 
en lingotes de bronce, aes rude, cuyo valor se apreciaba según el peso. Fue, pues, con la Ley de las XII Tablas que comenzó a acuñarse la moneda, en cobre, que se valuaban no ya por el peso, sino por el valor unitario y el número, pecunia numerata, y cuyo uso fue sustituyendo el uso de la moneda por peso. Posteriormente, aparecería la moneda acuñada en plata y en oro contribuyendo a que la compraventa como contrato se fuera afianzando en cuanto al pago del valor de las cosas en dinero, denares, acentuándose la diferencia entre la compraventa, emptio et venditio, y la permuta, permutatio ${ }^{2}$.

Según expone Petit, en torno a la permuta se produjo una controversia entre la Escuela de los Sabinianos y la de los Proculeyanos, que fueron las dos más famosas Escuelas de Derecho ${ }^{3}$. Según Carlos Rodríguez Pastor ${ }^{4}$, uno de los antiguos maestros sanmarquinos de la materia, la Escuela de los Sabinianos agrupaba a los jurisconsultos vinculados a la aristocracia imperial que, como discípulos de la filosofía peripatética, seguían el principio de autoridad, tanto en la Política como en el Derecho, se caracterizaba por la fidelidad a las piniones precedentes de los jurisconsultos que los habían precedido; mientras que la Escuela de los Proculeyanos congregaba a juristas alejados del favor imperial, estoicos en filosofía, que se caracterizaban por la rigidez de un raciocinio inflexible que los llevaba a aceptar las conclusiones lógicas de sus principios, siendo innovadores ${ }^{5}$.

En consecuencia, para la Escuela de los Sabinianos la permutiato era una venta, pues encontraba lógico dar el mismo tratamiento a todos los actos de enajenación a título oneroso, sea que el precio fuera pecunia numerata o que no lo fuera. Para la Escuela de los Proculeyanos, el criterio sabiniano distorsionaba las reglas de la emptio et vendione, siendo este el criterio que prevaleció en el Derecho Romano, que concretó un tratamiento dual entre la permuta y la compraventa y que recepcionaría la codificación civil moderna.

Sin embargo, y pese a la opinión de los proculeyanos, la permuta fue inmersa dentro de los contratos innominados. Según Rodríguez Pastor ${ }^{6}$ los contratos innominados debían presentar tres características: que hubiese una convención sinalagmática, que una de las partes hubiese cumplido y que la convención no constituyese un contrato nominado. Estos contratos, aún cuando receptaban viejas prácticas fueron lentamente reconocidos en el Derecho Romano, entre ellos la permutatio, que era expresión de un doy para que des, do ut des.

Como bien lo han expuesto los romanistas, los jurisconsultos romanos no fueron afectos a la abstracción sino a la consideración de los casos concretos y a las circunstancias dentro de las cuales debía

2. Vide de Eugene Petit, Tratado Elemental de Derecho Romano, (México DF: Ediciones Selectas, 1982), 389 y sgtes.

3. Ibídem.

4. Carlos Rodríguez Pastor. Prontuario de Derecho Romano, Fundación M. J. Bustamante de la Fuente, (Lima: 1992), 29 y 30.

5. Ibídem, 195 y 196.

6. Ibídem. 
ser declarado el derecho mediante la tutela jurisdiccional. Pero esto no significa, como puntualiza Juan Iglesias $^{7}$, que la tendencia hacia la concreción y la tipicidad de los juristas de Roma no haya determinado y aproximado determinadas figuras en las que se encontraba una cierta homogeneidad. Y así se fue perfilando la permuta, como cambio de cosa por cosa, como un contrato consensual que radicaba en dar, datio, recíproco de las partes.

La permuta fue quedando contractualmente conceptuada por la entrega de una cosa a cambio de otra y, no obstante la diferenciación con la compraventa, emptio venditio, le eran aplicables los principios de la evicción, de los vicios ocultos y del riesgo, quedando protegida por la actio praescriptis verbis, que hacía exigible la datio a la otra parte.

Los caracteres que fijó el Derecho Romano a la permuta fueron resultado de su diferenciación con la compraventa, tal como lo ha puntualizado Petit ${ }^{8}$. Así, por la manera como se configuraba el contrato, pues en la permuta se formaba después que una de las partes ejecutara voluntariamente la datio convenida, mientras que en la compraventa se formaba por el solo acuerdo de las partes y obligarse la parte vendedora a transferir la propiedad del bien, lo que ya hacía propietario a la otra compradora, a la que sólo podía exigírsele el pago del precio convenido; y, por los efectos, pues en la permuta se generaban los mismos para ambas partes al haber asumido la obligación recíproca de transferirse la propiedad de las cosas, quedando obligadas, además, al saneamiento por evicción y por vicios ocultos; mientras que en la compraventa los efectos eran distintos para el vendedor y el comprador, pues al vendedor sólo correspondía el saneamiento por evicción y vicios ocultos de la cosa que había transferido y, al comprador, el pago del precio.

La evolución del Derecho Romano prácticamente concluyó con la promulgación con la compilación realizada en la época del Emperador Justiano, el Codex Justinianeo, conocido como el Corpus Iuris Civiles, que es el antecedente histórico de la codificación civil moderna.

\section{LA RECEPCIÓN DEL DERECHO ROMANO}

La Historia del Derecho le da la denominación de Recepción del Derecho Romano al fenómeno de la admisión y penetración del Derecho Romano en los ordenamientos jurídicos de Europa, difundido por obra de la Escuela de los Glosadores a la que siguió la Escuela de los Postglosadores.

La Recepción del Derecho Romano significó que el Corpus Iuris Civiles fuera considerado como el Derecho Civil, pero, como apunta Federico Puig Brutau', en la parte que regulaba las relaciones entre sujetos privados, esto es, en la del Ius Privatum.

7. Juan Iglesias. Derecho Romano. Instituciones de Derecho Privado, 8va. Edición (Barcelona: Ariel, 1983), 178.

8. Eugene Petit, Tratado Elemental de Derecho Romano, op.cit., 420.

9. Federico Puig Brutau, Introducción al Derecho Civil, (Barcelona: Editorial Bosch, 1981), 57. 
El Derecho Romano también fue recepcionado por el Derecho Hispano y penetró en la península Ibérica, aunque fragmentado por las diversas invasiones que sufrió la península para ir unificándose en el Derecho de Castilla, pues fue el Derecho Castellano, que fue el trasplantado con la conquista española de los territorios hispano americanos y dio formación al denominado Derecho Indiano ${ }^{10}$, que es el antecedente del Derecho Civil formado con el advenimiento de las repúblicas formadas como consecuencia de la Emancipación de la Corona Española o, si se prefiere, Ibérica.

Para entonces el Corpus Iuris Civiles era ya un remoto antecedente y en Europa, desde mediados del siglo XVIII habían comenzado a formularse los primeros ordenamientos civiles integrados al Sistema del Derecho Romano al que está engarzado el Derecho Civil Peruano.

\section{LA CODIFICACIÓN CIVIL}

Según los historiadores del Derecho, la codificación civil, luego de algunos intentos, alcanzó su eclosión con el Código Civil Francés de 1804, el denominado Código Napoleón, que irradió una gran influencia en los nacientes Estados de la América Ibérica constituidos como consecuencia del movimiento emancipador ${ }^{11}$.

Por la vía del Código Francés el contrato de permuta fue receptado en la codificación civil peruana.

\section{EL CÓDIGO CIVIL DE 1852}

El Código Civil de 1852 es el primer ordenamiento civil peruano que tuvo una vigencia real y efectiva, iniciándola a partir del 29 de julio de ese año, receptando la influencia románica y napoleónica. Si bien fue precedido por el Código de Bolivia de 1831, este fue una réplica del Código Francés, por lo que puede afirmarse que, por su originalidad, es el primer código iberoamericano, pues antecedió al Código Chileno de 1857 y al Argentino de 1871.

Al ocuparse de la permuta, la conceptuó como un contrato por el que dos o mas personas se transferían el dominio de un cosa por otra (art. 1523), haciendo devenir la compraventa en permuta si el precio se pactaba parte en dinero y parte en bienes muebles o inmuebles, pero siempre que lo pagado en dinero no alcanzara la mitad de los bienes materia de la contraprestación (art. 1524). Distinguía la permuta en pura o simple y en estimada, según se considerara el valor de los bienes en dinero o si se hacía una comparación de los valores (art. 1525). Declaró permutables todos los bienes enajenables (art. 1526). La capacidad para permutar la fijó en la misma que para enajenar (art. 1527), pudiendo el administrador sólo realizar permutas simples o puras (art. 1528), siendo requisito, además, que los bienes permutables fueran conocidos por las partes (art. 1529). El Contrato quedaba concluido por el

10. Vide, Fernando Vidal Ramírez, Manual Introductorio al Derecho Civil Peruano, (Lima: 2012,IDEMSA),71 y sgtes. 11. Vide, Carlos Ramos Núñez, El Código Napoleónico y su recepción en América Latina, (Perú, Lima: Fondo Editorial de la Pontificia Universidad Católica del Perú, 1997). 
sólo convenio de las partes (art. 1530), con lo que dejó de ser un contrato real, esto es, que requería de la entrega recíproca de las cosas, como lo había previsto el Derecho Romano, y devino en un contrato consensual. Por último, el permutante quedaba obligado a la indemnización de dańos y perjuicios por la demora en la entrega del bien que estaba obligado a entregar (art. 1531), y, si no cumplía con la entrega, quedaba obligado, además, a devolver el bien que había recibido o a pagar su valor en dinero (art. 1532).

Adicionalmente, previó la permuta del bien ajeno disponiendo que en tal caso el otro permutante, si lo probaba, no estaba obligado a recibirlo ni a entregar el que había ofrecido, y, en caso de haberse efectuado la recíproca entrega, el contrato se rescindía y obligaba al pago de una indemnización (art. 1533). En cuanto al riesgo, atendiendo a su carácter consensual, dispuso que la mejora o deterioro del bien correspondía al permutante que lo había adquirido (art. 1534), salvo que la demora en la entrega del bien fuera imputable al otro permutante y perecía por su dolo o culpa (art. 1535). En relación a la evicción y saneamiento, cada permutante quedaba respectivamente obligado (art. 1536), quedando facultado el permutante afectado por la evicción a que se le devolviera el bien que había entregado o su valor en dinero, con mas los frutos y los daños y perjuicios que hubiera sufrido (art. 1537). Por último, previó la lesión como causal rescisoria, pero a la que se aplicarían las reglas de la compraventa (art. 1538), reglas que, en general, eran supletorias a la permuta (art. 1539).

Como puede apreciarse, la permuta no tuvo como característica ser un contrato real sino que fue legislado como consensual, al requerirse, tan sólo, del consentimiento para la formación del contrato. A pesar de que tuvo su propio régimen legal con una relativa autonomía se le vinculó a la compraventa. Dispuso una capacidad especial para su celebración y no le prescribió formalidades. Siendo la permuta fuente de obligaciones, le estableció reglas para el caso de su inejecución.

El Código Civil de 1852 tuvo 84 años de vigencia, aunque con importantes modificaciones, siendo derogado por el Código Civil de 1936.

\section{EL CÓDIGO CIVIL DE 1936}

El Código Civil de 1936 inició su vigencia el 14 de noviembre de ese año hasta su derogación por el Código Civil actualmente en vigencia.

Al contrato de permuta le dio un tratamiento diminuto pues se limitó, en su artículo 1465, a puntualizar que "Regirán en la permuta las disposiciones sobre compraventa en lo que le sean aplicables". Manuel Augusto Olaechea, su ponente, explicó que el tratamiento de la permuta no requería de mayor desarrollo ${ }^{12}$.

12. Manuel Augusto Olaechea, Exposición de Motivos del Libro Quinto del Proyecto de Código Civil, (Lima: Gil Editores, 1936), 43. 
José León Barandiarán, ante el tratamiento diminuto que había recibido el contrato de permuta fue de opinión que las normas de la compraventa no se debían aplicar pura y simplemente y que, por lo contrario, su aplicación debía hacerse con las adaptaciones necesarias, es decir, adecuando los preceptos en cuestión a la naturaleza específica del contrato de permuta, algunas veces con simples e insignificantes retoques, pero, en otras, precisando el principio de la norma de la compraventa para después deducir si el precepto era o no el adecuado a la permuta ${ }^{13}$.

\section{EL CONTRATO DE PERMUTA EN EL CÓDIGO CIVIL VIGENTE}

El Código Civil vigente fue resultado del proceso de reforma del Código Civil de 1936 iniciado en 1965 y concluido en julio de 1984 . Inició su vigencia el 14 de noviembre de $1984^{14}$.

El tratamiento que le dispensa al contrato de permuta es también diminuto siguiendo el antecedente del Código de 1936, pues le dedica los artículos 1602, en el que lo conceptúa, y el 1603, que como norma de remisión dispone la aplicación de las reglas del contrato de compraventa.

El acotado artículo 1602 al conceptuándola precisa que "Por la permuta los permutantes se obligan a transferirse recíprocamente la propiedad de bienes", de lo que se infiere la relación jurídica de índole obligacional que se enfatiza de conformidad con la sistemática adoptada por el Código.

El contrato, obviamente, también genera derechos para los permutantes quienes se los pueden oponer recíprocamente y, ambos, oponérselos a los terceros conforme a la doctrina del efecto relativo de los contratos que postula el artículo 1363 del Código.

La relación contractual puede extinguirse en el momento mismo de la celebración del contrato si su ejecución es instantánea o, puede ser continuada si las obligaciones, o una de ellas, va a tener una ejecución sucesiva.

Como puede apreciarse de la conceptuación de la permuta, se trata de un contrato con elementos constitutivos propios que le dan tipicidad, por lo que nos vamos a detener en ellos.

\section{LOS ELEMENTOS CONSTITUTIVOS}

Atendiendo a la conceptuación del contrato de permuta establecida por el acotado artículo 1602, en una interpretación sistemática de los artículos 1603 y 1531 del mismo Código, el elemento constitutivo viene a ser la intención de permutar, animus permutationem, y los bienes permutables.

La intención de permutar debe provenir de un sujeto con plena capacidad de ejercicio y sin ninguna de las restricciones que contempla la ley, conforme a la modificación del numeral 1 del artículo 140 del

13. José León Barandiarán, Tratado de Derecho Civil, (Lima:W.G. Editores, 1992) T. V, 153.

14. Vide, Fernando Vidal Ramírez, Manual Introductorio al Derecho Civil Peruano, op. cit, 107 y sgtes. 
Código Civil introducida por el Decreto Legislativo No. 1384. La intención de los permutantes, que constituye el fin o, mejor dicho, la finalidad del contrato, debe ser necesariamente lícita.

Los bienes permutables pueden ser muebles o inmuebles. Si son bienes muebles la transferencia de la propiedad requiere de su entrega, traditio, conforme al artículo $947^{15}$ del Código Civil y, si son inmuebles la propiedad se transfiere al prestar el permutante su consentimiento, conforme al artículo $949^{16}$ del mismo Código.

En relación a este segundo elemento constitutivo es conveniente aclarar que los bienes permutables no constituyen el objeto del contrato de permuta. Siendo la permuta un acto jurídico, porque todo contrato lo es, le son aplicables los requisitos de validez que enumera el artículo 140 del Código Civil ${ }^{17}$, entre ellos la posibilidad física y jurídica de su objeto, respecto del cual se ha establecido un criterio interpretativo en el sentido de que el objeto del acto jurídico es la relación jurídica a la que se incorporan los derechos y obligaciones que el acto jurídico, en este caso el contrato de permuta, genera o ha generado ${ }^{18}$. Con este criterio se interpreta también el artículo $1402^{19} \mathrm{y}$ es el adoptado por la doctrina nacional ${ }^{20}$.

Adicionalmente y en relación a este segundo elemento constitutivo de la permuta, es conveniente anotar que los bienes a que hace referencia el artículo 1602 no debe entenderse sólo a los bienes corporales sino también a los incorporales, que incluye a los derechos y no sólo al de propiedad.

El fin, o mejor, la finalidad que se pretende con la celebración del contrato de permuta, que no es otra que la adquisición de los bienes permutados, como ya se ha advertido, debe ser necesariamente lícita.

El Código Civil no le ha prescrito forma al contrato de permuta, por lo que los permutantes pueden celebrarlo con las formalidades que tengan por conveniente.

15. Art. 947: La transferencia de propiedad de una cosa mueble se efectúa con la tradición a su acreedor, salvo disposición legal diferente.

16. Art. 949: La sola obligación de enajenar un inmueble determinado hace al acreedor propietario de él, salvo disposición legal o pacto en contrario.

17. Art. 140: El acto jurídico es la manifestación de voluntad destinada a crear, regular, modificar o extinguir relaciones jurídicas. Para su Validez se requiere: 1. Plena capacidad de ejercicio, salvo las restricciones contempladas en la ley. 2. Objeto física y jurídicamente posible. 3. Fin lícito. 4. Observancia de la forma prescrita bajo sanción de nulidad.

18. Vide, Fernando Vidal Ramírez, El Acto Jurídico, 11 Ed. (Lima: Edición Rimay, 2019), 152 y sgtes.

19. Art. 1402: El objeto del contrato consiste en crear, regular, modificar o extinguir obligaciones.

20. Vide, de Max Arias Schreiber, "Exégesis del Código Civil Peruano", Gaceta Jurídica, Lima, (1995) T. I, 154 y sgtes y de Manuel de la Puente y Lavalle, El Contrato en General. Primera Parte, (Lima: Fondo Editorial de la Pontificia Universidad Católica del Perú, 1993),T. III, 285 y sgtes. 
Los propiamente elementos constitutivos de la permuta le dan una tipicidad que determina su diferencia con la compraventa, pues siendo enajenativa carece del elemento distintivo que es el precio, esto es, la entrega de una suma de dinero como postulada por León Barandiarán ${ }^{21}$ en sus comentarios al Código Civil de 1936, siguiendo el criterio expuesto por Ángel Gustavo Cornejo ${ }^{22}$.

Los mismos elementos constitutivos determinan que la tipicidad de la permuta establezca su diferencia con cualquier otro contrato o figura jurídica, por lo que determinados sus elementos constitutivos corresponde detenernos en sus características.

\section{CARACTERÍSTICAS DEL CONTRATO DE PERMUTA}

La permuta es, en primer lugar, un contrato bilateral y sinalagmático, no sólo porque se genera con la manifestación de voluntad de los permutantes sino porque además genera obligaciones para ambas partes, como son las de transferirse la propiedad de los bienes que permutan. Es un contrato nominado, en cuanto el Código Civil lo legisla con un nomen iuris y lo somete a un régimen legal.

Puede ser real o consensual, según los bienes que se permutan sean muebles, cuya transferencia requiere de la tradición, o inmuebles, cuya transferencia requiere sólo del consentimiento, como lo hemos dejado establecido anteriormente.

Es un contrato enajenativo y oneroso, porque dispone de la propiedad de los bienes con reciprocidad de prestaciones, lo que lo hace también constitutivo porque genera obligaciones y derechos.

Por último, puede ser un contrato conmutativo o aleatorio, en la medida de que los bienes permutados tengan equivalencia o no la tengan e impliquen un riesgo, alea.

\section{LAS DISPOSICIONES APLICABLES}

La permuta, como todo contrato, se sustenta en la autonomía de la voluntad privada y, en consecuencia, los permutantes pueden darle al contenido del contrato los pactos que tengan por conveniente siempre que no colisionen con normas de orden público, conforme a lo previsto en el artículo 1354 del Código Civil ${ }^{23}$.

Como hemos visto anteriormente, el artículo 1603, genuina norma de remisión, le atribuye a la permuta las reglas de la compraventa en lo que le sean aplicables. La cuestión radica en determinar si las reglas aplicables son estrictamente las de la compraventa o si le son de aplicación, en general,

21. José León Barandiarán. Tratado de Derecho Civil, op. cit., pág. 151.

22. Vide de Fernando Guzmán Ferrer. Código Civil (1936). Exposición de Motivos. Comentarios. Doctrina, 4ta. Edición, (Lima: Cultural Cuzco, T.III), 1656 y 1657.

23. Art. 1354: Las partes pueden determinar libremente el contenido del contrato, siempre que no sea contrario a norma legal de carácter imperativo. 
la normativa pertinente del Código Civil en materia de acto jurídico y, en especial, la de los contratos en general, que en mi opinión lo son, pues la acotada norma debe ser interpretada extensivamente.

En relación a las reglas de la compraventa son aplicables todas las que se deriven de la autonomía de la voluntad de los permutantes y que sean compatibles con los elementos constitutivos de la permuta. Así, por ejemplo, los gastos de entrega de los bienes permutados (art. 1530); pueden permutarse los bienes existentes o que puedan existir, siempre que sean determinados o determinables y cuya enajenación no esté prohibida por la ley (art. 1532); el derecho del permutante a retractarse en caso del perecimiento del bien al celebrarse el contrato (art. 1533); la permuta de bien futuro (arts. 1534 y 1535) y de bien ajeno (art. 1539); la obligación del permutante de perfeccionar la transferencia del bien permutado y su entrega (arts. 1549, 1550,1551, 1554. 1556); la transferencia del riesgo (arts. 1567 y 1570). Puede celebrarse a satisfacción de uno o ambos permutantes (art. 1571), también a prueba (art. 1572), sobre muestra art. (1573) y sobre medida (art. 1574). Por último, son aplicables también las normas para el ejercicio del derecho de retracto (arts. 1592 y siguientes).

En materia de acto jurídico le es aplicable al contrato de permuta la normativa contenida en el Libro II del Código Civil., pues además de los requisitos de validez, de los que ya nos hemos ocupado, nada obsta para que pueda celebrarse mediante representación, que se pacten modalidades, que pueda simularse o celebrarse en fraude de acreedores, que los permutantes incurran en vicios de la voluntad o que al contrato le sean aplicables las causales de nulidad o de anulabilidad.

En relación a las reglas generales de los contratos, esto es, las comprendidas en la Sección Primera del Libro VII del Código Civil., es obvio que le son aplicables todas las que corresponden a la etapa de las tratativas, esto es, a la oferta y su aceptación, así como las de la formación del contrato. Así, nada impide que la permuta se defina en base a un contrato preparatorio, trátese de un compromiso de contratar (art. 1414) o de un contrato de opción (art. 1419), háyase o no pactado arras (arts. 1477 y 1480.). Siendo la permuta un contrato con prestaciones recíprocas le son aplicables las normas que las rigen (arts. 1426 a 1434). Los permutantes pueden ceder su posición contractual (arts. 1435). Si el contrato es conmutativo y de ejecución continuada, nada obsta para que pueda alegarse la excesiva onerosidad de la prestación (arts. 1440) o lesión para rescindirlo (arts. 1447). Por último, los permutantes están obligados al saneamiento (art. 1484), sea por evicción (art. 1491) o por vicios ocultos (art. 1503).

\section{CONCLUSIÓN}

Como puede colegirse la permuta es un contrato con raigambre romanista y recepcionado por la codificación civil. El Código Civil de 1852 le dio un tratamiento de acuerdo a sus antecedentes romanistas lo que no hizo el Código Civil de 1936, que le dio un tratamiento diminuto que el actual Código Civil ha mantenido, aunque le da una conceptuación.

Como se ha visto al ocuparnos de los elementos constitutivos, estos no se infieren sólo del artículo 1602 del Código Civil de 1984 sino que hemos tenido que recurrir a su artículo 1531 para tomar de él 
la intención de permutar, por lo que consideramos que debió ser instalado en el Título II de la Sección Segunda del Libro VII que norma el contrato de permuta atendiendo al antecedente determinado por el artículo 1524 del Código Civil de 1852 y a la doctrina sentada por Angel Gustavo Cornejo y José León Barandiarán.

\section{REFERENCIAS}

- Arias Schreiber, Max. “Exégesis del Código Civil Peruano”. Gaceta Jurídica. Lima, (1995).

- De la Puente y Lavalle, Manuel. El Contrato en General. Primera Parte T. III. Lima: Fondo Editorial de la Pontificia Universidad Católica del Perú, 1993.

- Guzmán Ferrer, Fernando. Código Civil (1936). Exposición de Motivos. Comentarios. Doctrina, 4ta. Edición. T: III. Lima: Cultural Cuzco.

- Iglesias, Juan. Derecho Romano. Instituciones de Derecho Privado, 8va. Edición. Barcelona: Ariel, 1983.

- $\quad$ León Barandiaran, José. Tratado de Derecho Civil. Lima:W.G. Editores, 1992 T. V.

- Olaechea Manuel Augusto. Exposición de Motivos del Libro Quinto del Proyecto de Código Civil. Lima: Gil Editores, 1936.

- Petit, Eugene. Tratado Elemental de Derecho Romano. México DF: Ediciones Selectas, 1982.

- $\quad$ Puig Brutau, Federico. Introducción al Derecho Civil. Barcelona: Editorial Bosch, 1981.

- $\quad$ Ramos Núnez, Carlos. El Código Napoleónico y su recepción en América Latina. Lima: Fondo Editorial de la Pontificia Universidad Católica del Perú, 1997.

- Rodríguez Pastor, Carlos. Prontuario de Derecho Romano. Fundación M. J. Bustamante de la Fuente, 2a . ed. Revisada. Lima: Ed. Cultural Cuzco S.A.,1992.

- Vidal Ramírez, Fernando. Manual Introductorio al Derecho Civil Peruano. Lima: IDEMSA, 2012.

- Vidal Ramírez Fernando. El Acto Jurídico. 11 Ed. Lima: Ediciones Rimay, 2019.

RECIBIDO: $10 / 09 / 2020$

APROBADO: 08/10/2020 


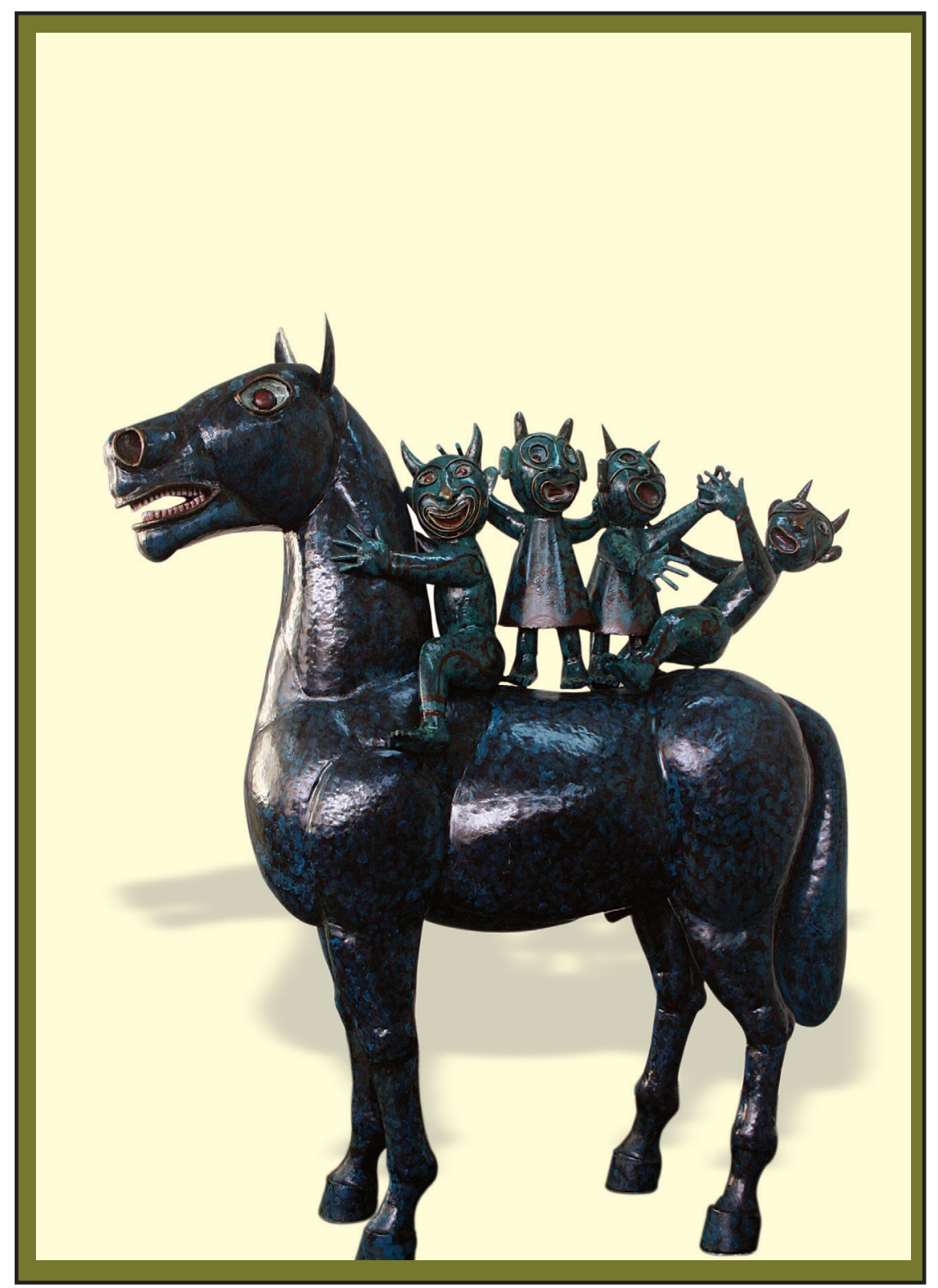

Los hermanos Ayar. Escultura, hierro y bronce, 1999. Artista plástico peruano, Alberto Quintanilla (Cusco, 1934). 